session was held during the NAPCRG Annual Meeting in New York, NY on November 24, 2014. The goal of the session was to inspire and inform NAPCRG members about how to get more involved in the organization. The session provided an overview of NAPCRG's history, culture and personal testimonials from current and past leaders about the importance of the organization. Information was shared on how to get involved in special interest groups, committees, and the Board of Directors. The session was well attended and will be repeated at future Annual Meetings.

The final stage of the expansion of NAPCRG's leadership capacity is improvement to the committee and subcommittee structure. Historically, each committee chair determined who was on their committees, and often members who expressed interest in serving on a committee were never contacted regarding their interest. As a result, the board approved a new policy that will require each committee chair to determine the optimal size of their committee and type of members they need to meet their needs. Chairs will also determine a fair and transparent election or selection process. Members will serve on committees for 2 twoyear terms and during the open call for nominations to the board there will now be an open call for nominations for all open seats on committees. Nominations for committee positions will be sent to each committee chair to elect nominees.

The Board of Directors and the Executive Director will regularly evaluate and refine these new processes and procedures for improving NAPCRG's leadership capacity, and every effort will be made to identify opportunities to further the mission of creating an environment for all members that is nurturing, informative and inspiring.

Tom Vansagbi, PbD

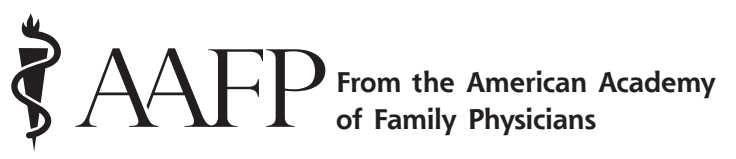

Ann Fam Med 2015;13:390-391. doi: 10.1370/afm.1826.

\section{FAMILY PHYSICIAN SALARIES UP, BUT STILL TRAIL THOSE OF SUBSPECIALISTS}

Family physicians are earning more than they did last year, with salaries that are growing faster than those for most other specialists, according to an annual survey on physician compensation. Still, the income gap between family physicians and other specialists remains wide.
On average, primary care physicians overall-and family physicians, specifically-earn $\$ 195,000$ annually, compared with $\$ 284,000$ for physicians in other specialties, the 2015 Medscape Physician Compensation Report (http://www.medscape.com) found. Pediatricians were the only specialty with a lower average salary, at $\$ 189,000$ per year. However, salaries for family physicians rose $10 \%$ between 2014 and 2015, the fifth-highest rate of increase for any specialty.

Nearly 20,000 physicians participated in the survey, which was conducted from December 30, 2014, to March 11, 2015. Of the participating physicians, family physicians and internists made up the highest volume of respondents, with each specialty comprising $12 \%$ of total respondents.

\section{Need for Value-based Compensation}

"The survey demonstrates that the importance of family medicine continues to be undervalued by the health care system," said AAFP President Robert Wergin, MD, of Milford, Nebraska. "There is hope that with passage of the MACRA (Medicare Access and CHIP [Children's Health Insurance Program] Reauthorization Act) legislation, there will be a movement away from the volume-based, fee-for-service world that is focused on acute illness and episodic care to a payment system that is value-based, and this will improve the compensation and value of family physicians."

As it stands, $47 \%$ of primary care physicians think they are compensated fairly, compared with $50 \%$ of other specialists.

It is worth noting that a physician's practice situation exerts a significant influence on annual compensation. Primary care physicians who are employed earn an average of $\$ 189,000$ annually compared with $\$ 212,000$ for self-employed physicians.

In addition, family medicine ranks sixth among specialties in employing the highest percentage of female physicians, at $35 \%$. Unfortunately, however, the gender-based income gap in medicine continues, with male physicians across all specialties earning, on average, $\$ 55,500$ more than female physicians.

"There is a disparity in our profession, and as an Academy, we have to keep advocating for equal pay for equal work," Wergin said. "We're behind, and not just in family medicine."

\section{Focus on Other Practice Issues}

The survey covered much more than salary issues, also focusing on hours spent with patients and overall career satisfaction. Several questions focused specifically on primary care, including family medicine.

For example, $34 \%$ of family physicians said they spend between 13 and 16 minutes with each patient, 
another $23 \%$ reported they spend 17 to 20 minutes per patient, and $22 \%$ said they spend 9 to 12 minutes with each patient. Primary care physicians overall devote considerable time to paperwork and administration, with $33 \%$ of self-employed and $27 \%$ of employed primary care physicians reporting that it takes 10 to 14 hours per week.

Regarding career satisfaction, family physicians ranked highest in terms of saying they would choose a career in medicine again, with $73 \%$ reporting that they would. But only $32 \%$ of family physicians said they would choose the same specialty.

AAFP President-elect Wanda Filer, MD, MBA, of York, Pennsylvania, said that although she was "thrilled" to see that family physicians were the specialists most likely to say they would choose medicine again, she was concerned that so few of them would again choose family medicine as their specialty. She chalked it up to the stress of navigating an increasingly complex practice environment.

"I know that burnout is a huge issue, brought on, at least in part, by ridiculous administrative burdens that take us away from rewarding face-to-face time with patients- the real reason we went into medicine," Filer said.

Filer is encouraged to see residents and students "who are ready to change the world," but cautioned that more needs to be done to ensure that family physicians who have been in practice for a while retain that same enthusiasm.

"It is important to help all of our members rediscover and sustain the joy of practice," she said. "We work daily to mitigate those many burnout factors coming from the practice front."

According to the survey report, family physicians ranked eighth overall in terms of offering new ancillary services_-such as MRI, physical therapy, orthotics, or in-office surgery-in their practice in the past 3 years, with $23 \%$ saying they have offered a new service during that period.

The report also noted that overall physician participation in accountable care organizations (ACOs) continues to grow at a rapid rate, with the percentage increasing from just 3\% in 2011 to $30 \%$ in the 2015 survey report. Among primary care physicians, 35\% said they participated in an ACO.

Wergin remains optimistic that policy changes at the federal level and a shift toward a greater emphasis on primary care worldwide are promising trends.

"Our value is going to increase as it is already recognized in every other developed country in the world," he said. "Countries such as Canada and England realized you cannot build a health care delivery system without a strong primary care base, and they reimburse their primary care physicians in line with that value.

"We're behind those systems now, but we're moving in their direction."

\author{
Michael Laff \\ AAFP News Department
}



Ann Fam Med 2015;13:391-392. doi: 10.1370/afm.1828.

\section{THE AMERICAN BOARD OF FAMILY MEDICINE FOUNDATION INAUGURATES THE G. GAYLE STEPHENS KEYSTONE CONFERENCE SERIES}

Dr Gayle Stephens (August 6, 1928-February 20, 2014), one of the founders of family medicine in the United States, provided consistent intellectual leadership that profoundly impacted the specialty. He connected history, philosophy, religion, psychiatry, the family, the community, and the sciences to the practice of medicine, and he explained how family medicine was a counter-culture within medicine, manifested in personal relationships and rooted in social change. He particularly advanced the importance of relationships in clinical practice and the role of the personal physician as a trusted and trustworthy agent for patients. His obituary proclaimed:

Through his practice, teaching, writing, editing, and advocacy, Dr Stephens acted on his belief that, "Medicine is a moral vocation that is practiced best when patients have a personal physician who can help them get what they need from the larger system in a manner that does not demean or exploit them, a personal physician who is able and willing to attend to their patients' life experiences and individual preferences."

Dr Stephens was a prolific writer and his extensive body of written work was highlighted in a 2011 Family Medicine article, "G Gayle Stephens Festschrift," written by John Geyman, MD, another founding leader in family medicine and contemporary of Dr Stephens. Dr Geyman wrote that Dr Stephens:

"has been...by far the most original, thoughtful, and eloquent voice in our field and among the few who best represents the moral conscience of the entire medical profession. His wide-ranging intellect connects us with history, gives 